\title{
Can Smart City Policy Facilitate the Low-Carbon Economy in China? A Quasi-Natural Experiment Based on Pilot City
}

\author{
Shuangshuang Fan $\mathbb{D}^{1},{ }^{1}$ Shengnan Peng, ${ }^{1}$ and Xiaoxue Liu $\mathbb{D}^{2}$ \\ ${ }^{1}$ School of Management, China University of Mining and Technology-Beijing, Beijing 10080, China \\ ${ }^{2}$ School of Economics, Beijing Technology and Business University, Beijing 100048, China \\ Correspondence should be addressed to Xiaoxue Liu; liuxx@th.btbu.edu.cn
}

Received 22 March 2021; Revised 23 June 2021; Accepted 6 July 2021; Published 14 July 2021

Academic Editor: Baogui Xin

Copyright $\odot 2021$ Shuangshuang Fan et al. This is an open access article distributed under the Creative Commons Attribution License, which permits unrestricted use, distribution, and reproduction in any medium, provided the original work is properly cited.

\begin{abstract}
This paper studies the impact of the implementation of smart city policy (SCP) on the development of low-carbon economy (LCE) in China. For this purpose, we developed a nonconvex meta-frontier data envelopment analysis (DEA) approach to measure LCE and used the differences-in-difference (DID) analysis method in the econometric model to empirically analyze the impact of SCP on LCE, using the dataset of 230 cities from 2005 to 2018. The results show that the implementation of SCP can significantly improve the LCE of cities, and the dynamic effect test presents that the promotion of smart cities to low-carbon economy increases with time. In addition, SCP promotes the development of LCE by optimizing government functions and improving the efficiency of governance and the degree of implementation openness. But there is heterogeneity between different cities as follows: the implementation of SCP has a more significant effect on the promotion of LCE in central and western regions in China and largescale cities and cities without strict environmental protection planning. Finally, the robustness test verifies the reliability of the experimental data again and puts forward conclusions and policy recommendations.
\end{abstract}

\section{Introduction}

Since human society entered the 21 st century, the process of urbanization has developed rapidly. Global population growth is mainly concentrated in urban areas. It is estimated that, by 2050, two thirds of the world's population will live in cities [1]. As the most populous country in the world, China's rapid economic development has promoted the rapid process of urbanization since reform and opening-up. By 2019, China's urbanization rate has reached $60.6 \%$, followed by a series of "urban diseases," such as resource shortage, environmental pollution, and ecological imbalance [2]. It is obvious that, in the process of urbanization, economic development has produced a lot of carbon dioxide emissions and the resulting greenhouse effect and extreme weather. How to solve the above problems and improve the environmental quality of the city and the sustainable development of the economy has been the topic of concern of scholars. In recent years, driven by new technologies such as Internet of Things, big data, block chain, and cloud computing, the concept of smart city emerges as the times require, providing opportunities for the operation of low-carbon economy.

By integrating new technologies into the management and operation of cities, smart cities provide innovative solutions for the sustainable development and low-carbon operation of cities. It promotes the low-carbon economy by optimizing the supply and demand of energy and information sharing between government, enterprises, and citizens [3]. In other words, smart city policy provides a way to solve multiple urban diseases, that is, cities can achieve innovation and sustainable development goals while maintaining economic development, so as to enhance competitiveness, for example, improving energy efficiency, developing new energy, reducing carbon emissions, and improving the quality of life of urban residents [4]. Based on this background, the Chinese government began to implement the pilot policy of smart city in 2012 and vigorously 
promote the construction of smart city. By the beginning of April 2020, the number of smart city pilot projects announced by the Ministry of Housing and Urban Rural Development of China has reached 290, and with the accelerated penetration of pilot policies, 800 smart pilot cities will be implemented in China in the near future, and China has become the largest smart city construction implementation country in the world. Do so many smart cities improve the quality of urbanization? Has it improved the effectiveness of urban management and the quality of life of citizens? Does it promote the development of low-carbon economy? This leads to a series of questions.

However, although the academic research on smart city shows an increasing trend, the empirical research in the existing literature is relatively scarce. At present, the research on smart city mainly focuses on the interpretation of the concept, construction planning, evaluation index system, strategic planning, and management measures, as well as the application of new science and technology in the construction of smart city $[5,6]$. And, some studies have pointed out that the development of smart city can improve energy efficiency [7], as well as promoting sustainable development $[8,9]$. There is little research on the impact of smart city policy on urban low-carbon economic development through empirical research.

The purpose of this paper is to evaluate whether the smart city policy improves the low-carbon economic development level of the city. The main contribution of this paper not only enriches the research results in related fields but also has certain reference value for the planning, managers, and decision makers of low-carbon cities and smart cities. The residual structure of this paper is arranged as follows: Section 2 is literature review and mechanism analysis, which systematically reviews the literature related to smart city and low-carbon economy and analyzes the mechanism of the impact of smart city construction on lowcarbon economy. Section 3 is the method and data. This paper establishes a DEA low-carbon economy measurement model and constructs an econometric model to analyze the research data. Section 4 is the result and discussion, including the evaluation of low-carbon economy, the impact of smart city on low-carbon economy, heterogeneity analysis, and robustness test. Section 5 is the conclusion and enlightenment. The conclusions and policy implications are summarized. The flowchart of this paper is shown in Figure 1.

\section{Literature Review and Theoretical Fracture}

At present, scholars have performed a lot of research on the concept, measurement, influencing factors, and economic and social effects of low-carbon economy. Although the expression of low-carbon economy in the existing literature is different, the basic point of view is the same, that is lowcarbon economy is based on low energy consumption, low pollutants, and carbon emissions, considering both economic development and sustainable economic growth mode [10]. It emphasizes the efficient use of energy and the development of new energy to achieve green GDP and maximize social output. And, afterwards, research on the measurement and evaluation of low-carbon economy is also quite rich. For instance, in terms of statistical evaluation methods, $\mathrm{Yu}$ et al. [11] introduced the fuzzy fractional differential equation in the construction of the statistical evaluation system of low-carbon economy to quantitatively evaluate the low-carbon economy. In [12], a novel economy and $\mathrm{CO} 2$ emissions evaluation model based on the slacksbased measure integrating the data envelopment analysis (SBM-DEA) is proposed to analyze and optimize energy structures of some countries and regions in the world. In terms of index evaluation methods, Mohsin et al. [13, 14] developed an aggregated composite index (ACI) of energy security and environmental sustainability for each of the world's highest GHGs and CO2-emitting countries by a comprehensive set of indicators including carbon emission and energy metrics.

Based on the accurate measurement of low-carbon economy, many scholars have studied the influencing factors of low-carbon economy from different perspectives. These factors can be roughly divided into technology level, industrial structure, economic and financial development level, population factor, and government policy. For instance, in terms of technology, many scholars [15-17] used econometric methods to test the impact of technological progress on environmental performance. They found that the increase of research and development investment and the invention of low-carbon patented technology can significantly improve the environmental performance of polluting industrial enterprises. As for the impact of the industrial structure on low-carbon economy, due to the different definitions of the industrial structure, the research conclusions are inconsistent. These conclusions include that the increase of the proportion of the secondary industry will increase carbon emissions [18], industrial growth and energy consumption have a significant positive impact on carbon emissions in the long and short term [19], the U-shaped correlation between industrial structure and carbon emissions [20], and the optimization of the industrial structure has no significant impact on carbon emissions [21]. In addition, economic and financial development has a positive effect on low-carbon economy [22-25]. Some studies have pointed out that population aging, population migration, and population structure have an impact on low-carbon economy [26-28]. In addition, in terms of government policy, some study [29] point out that government regulation and incentive policies will promote the innovation of low-carbon behavior and low-carbon technology of enterprises and then promote the development of low-carbon economy.

According to the current situation of urbanization in China, the sources of urban carbon emissions can be roughly divided into economic sources and policies, such as industrial carbon emissions (E1), transportation carbon emissions (E2), personal and household consumption carbon emissions (E3), building carbon emissions (E4), and policy sources such as urban expansion with low density and high energy consumption (E5) [30-32]. In terms of 


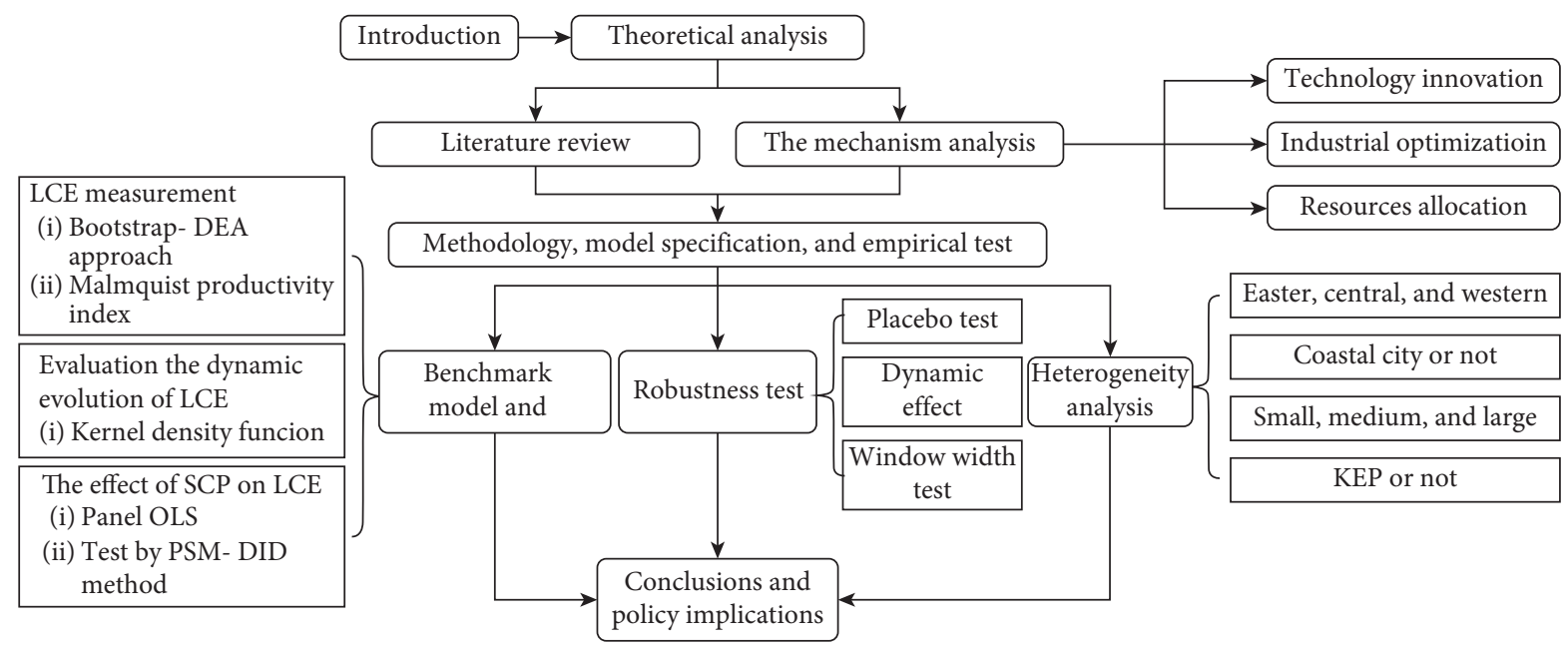

Figure 1: The flowchart of this paper.

industrial production, since 2003, China has accelerated the development of heavy industry, especially energy, raw material industry, and manufacturing industry, resulting in a large amount of carbon emissions. In addition, China's traditional export trade is dominated by processing industries with high energy consumption, which also leads to the increase of energy consumption. In the construction industry, there are a large number of buildings with high energy consumption and repeated urban construction in the process of urbanization, and inefficient use of buildings will lead to waste of building materials and carbon emissions. In terms of transportation, the acceleration of urban logistics circulation and the increase of traffic congestion have led to the rapid increase of transportation energy consumption. In terms of personal and household consumption, the increase of urban population will lead to the increase of residents' energy consumption. Finally, due to the low-density urban sprawl, the local government has pushed up the increase of carbon emissions in the process of urbanization $[33,34]$. The population density of 30 major cities in China has declined in the past 30 years, and the urban area has expanded faster than the population has increased. The marginal per capital energy consumption of urban expansion does not decrease but increases. Based on above analysis, the total carbon emissions (TE) in the process of urbanization can be expressed as $\mathrm{TE}=E 1 * E 2 * E 3 * E 4+E 5$, which will hinder the sustainable economic growth and is not conducive to the operation of low-carbon economy (shown in Figure 2).

Although some factors, such as technology level and government policy, are related to smart city, there are few studies on the impact of smart city policy on low-carbon economy, especially in China. Referring to [35], this paper argues that smart city policy may affect the operation of lowcarbon economy through the following channels (shown in Figure 3).

2.1. To Improve Energy Efficiency through a Series of Technological Innovation. As human society enters the era of Industry 4.0 , the concept of smart city and many new technologies are integrated, which realize the information sharing among the government, enterprises, and residents, for example, the use of Hadoop software for energy information management to monitor energy dynamics through the Internet of Things (IoT) and big data to achieve real-time monitoring of energy consumption terminal, so as to optimize energy storage and distribution. In addition, devices in smart cities are embedded with self-sustaining and automated sensors. The integration of physical devices, services, and management can be achieved with the help of network physical systems. Through these technological innovations, to improve energy efficiency and effective distribution of energy and to reduce urban carbon emissions, Babar and Khattak [36] proposed an overall design scheme of smart city energy management based on Internet of Things, ensured the energy efficiency of IOT equipment through data analysis, and constructed a model composed of energy management, data processing, and service management. It is verified that the model can achieve energyefficient clustering, peak shaving, optimal scheduling, and load balancing optimization. Luo et al. [37] proposed a short-term energy prediction system based on edge computing architecture. The system distributes data acquisition, data processing, and regression prediction on sensor nodes, routing nodes, and central servers, respectively. Semantic and stream processing technologies are used to support efficient data acquisition and processing in the IOT. And, some studies [38-40] have verified that blockchain technology provides an unchangeable account book for security value transactions in the smart city network. This time, grassroots technology can improve the efficiency of various processes in the energy sector. Therefore, blockchain technology promotes the innovation and transformation of the energy market and realizes the point-to-point energy microgrid, thus reducing urban energy consumption. In addition, academic research [41-43] has found that smart cities have more professional applications and spillover effects of technological innovation, thus improving the utilization efficiency and output level of resources, such as clean energy and clean technology. Meanwhile, cities are 


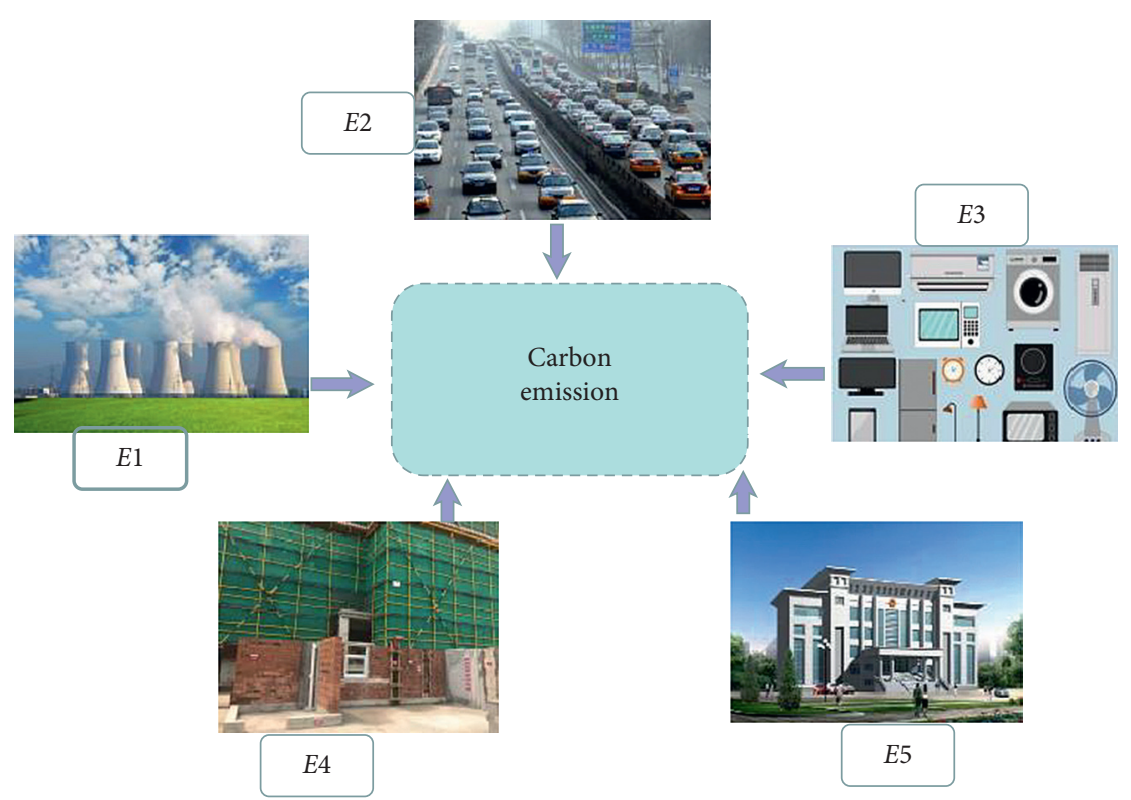

FIgURE 2: Main sources of carbon emission in the urbanization process.

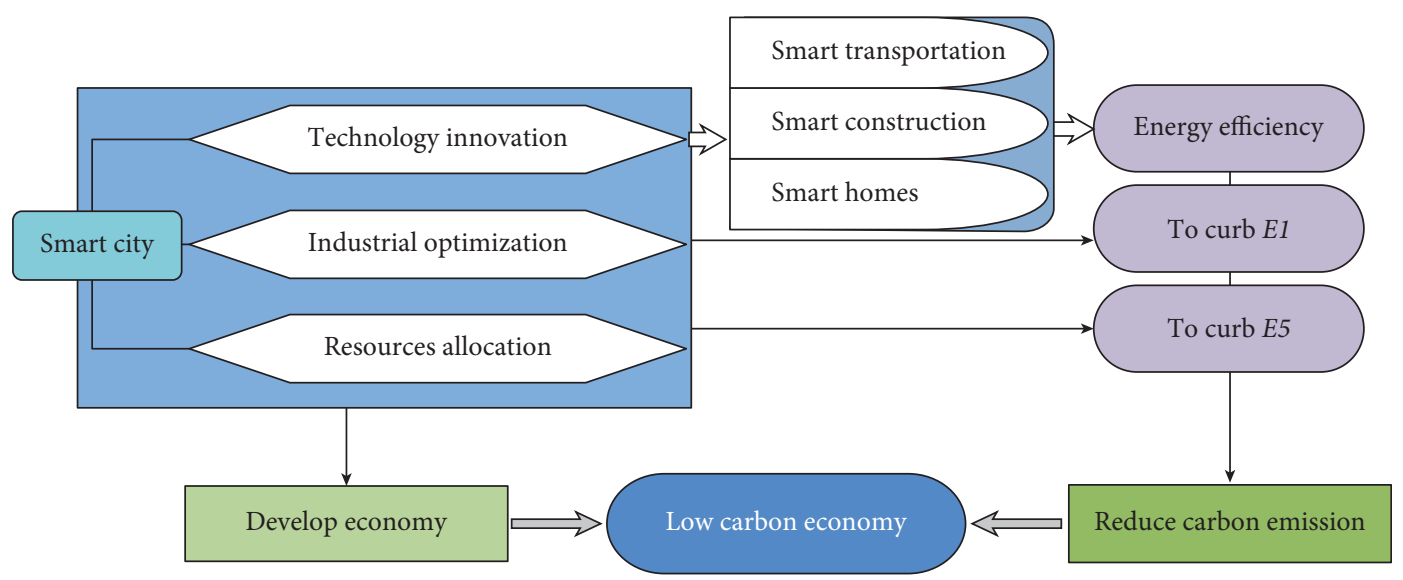

FiguRe 3: Theoretical framework for the effect of smart city construction on low-carbon economy.

conducive to transforming the mode of urban governance with the latest technologies which make the pollution regulation more efficient [44].

Smart transportation, smart buildings, and smart homes based on smart city technologies can effectively curb the carbon emissions brought by E2, E4, and E3. For E2, intelligent transportation uses the traffic data application system to realize data and information sharing among management departments, so as to optimize vehicle scheduling and reduce carbon emissions caused by congestion. In addition, smart cities promote the development of sharing economy and give birth to shared cars, shared logistics, and other formats to reduce urban energy consumption. For E4, smart cities realize the integration of urban construction industry, ecology, environmental optimization, and energy saving and consumption reduction through system technologies such as green energy-saving building technology, prefabricated building technology, and big data intelligent management. For E3, on the one hand, smart home realizes interconnection, remote control, intelligent analysis, low carbon, and energy saving of various household appliances based on intelligent analysis of big data. On the other hand, the distributed energy system is more convenient for users to use distributed power sources such as solar energy and wind energy, as a supplementary form of household electricity, to shift the peak load and fill the valley and reduce urban carbon emissions.

\subsection{To Reduce Carbon Emission through Industrial Structure} Optimization. Smart city construction not only promotes the overall economy $[42,45]$ but also optimizes the industrial structure. First of all, smart city will attract highquality material capital and investment and human capital to pilot cities, which will become the basis for the transformation and upgrading of the urban industrial structure. And, smart city construction optimizes the industrial results by upgrading the secondary industry and upgrading the 
high-end service industry in the tertiary industry. In $[46,47]$, the authors pointed out that smart city will attract investment and talent inflow and provide support for accelerating the optimization of the industrial structure. With the knowledge spillover effect of human capital, it improves the innovation and $R \& D$ ability of traditional industries and makes the industrial structure more advanced and less energy consuming. Secondly, smart city integrates the development of Internet of Things, big data, new energy, information materials, and other industries $[47,48]$, which will promote the prosperity of corresponding services, for example, research and development of information technology, software development, and mobile communication operation. Based on these technologies, it will promote the development of knowledge intensive industries with high added value and low energy consumption, thus reducing the carbon emission intensity of cities. Finally, the construction of smart city promotes the development of smart industry and smart consumption, for example, smart transportation, smart health care, smart education, and smart public services. These industries are based on the Internet and belong to technology intensive industries with low dependence on energy. The development of these industries has reduced the carbon emission intensity and environmental pollution caused by $E 1$.

\subsection{To Allocate Resources for Achieving Low-Carbon Eco-} nomic Development. Many network physical systems of smart city can solve the coupling problem of resource management by providing resource allocation efficiency [49-51]. For instance, Jing [52] proposed a resource optimization scheduling and allocation for the hierarchical distributed cloud service system in smart city, and the scheduling optimization and utilization efficiency of various resources in the hierarchical distributed cloud service for the smart city effectively reduces the response time of the tenant resource request and optimizes the performance of system resource scheduling on the cloud platform. Similarly, Kunst et al. [53] studied the improving network resources allocation in smart cities video surveillance. Intelligent transportation, intelligent government, intelligent logistics, and functional industrial park based on Internet of Things technology and big data can effectively relieve traffic pressure, greatly improve the operation speed of logistics, people flow, and information flow, reduce the circulation cost of resources, reduce the energy consumption per unit GDP and environmental protection cost, and provide support conditions for urban green development. From the market level, with the help of Internet of Things sensors, cloud computing, and big data analysis, urban enterprises can understand customers' latest demand and preference for products, so as to adjust their production behavior appropriately and promote the balance of resource supply and demand. When more high-quality information resources, knowledge resources, and human resources are gathered in smart cities, the efficiency of government planning and decision-making is improved, thus reducing the carbon emissions brought by
E5. In summary, smart city can reduce excessive energy consumption and emissions by optimizing resource allocation, so as to improve the development level of low-carbon economy.

\section{Methodology and Data}

3.1. Bootstrap-DEA Model for Low-Carbon Economy Measurement. By referring to existing studies, we find that most of previous papers use low-carbon total factor productivity, which is calculated by DEA, to measure LCE $[54,55]$; this paper estimates the development of LCE by establishing the bootstrap-DEA model and calculating the Malmquist productivity index. The advantage of this method is to simulate the production process with multiple outputs and inputs simultaneously and avoid the error of model setting caused by the parameterized method and the clear assumption that random interference items may not obey normal distribution. And, the low-carbon total factor productivity is measured by MATLAB software in this study. Considering that urban LCE will involve energy consumption, capital input, labor input, economic development, carbon dioxide emission, and afforestation to achieve carbon neutrality, we adopt labor $\left(x_{1}\right)$, capital $\left(x_{2}\right)$, and energy $\left(x_{3}\right)$ as inputs, GDP $\left(x_{4}\right)$ and afforestation area $\left(x_{5}\right)$ as desirable outputs, and carbon emissions $\left(x_{6}\right)$ as undesirable outputs. The function of the low-carbon total factor growth rate is expressed as

$$
\mathrm{ML}=F\left(x_{1}, x_{2}, x_{3}, x_{4}, x_{5}, x_{6}\right) .
$$

Among the input indicators, the labor means the number of people employed in the city in each year, and the unit is 10,000 people. And, the energy consumption is expressed by converting the carbon energy consumed by cities into standard coal, and the unit is 10,000 tons. The capital is calculated by the perpetual inventory method, and we take the year 2000 as the base year, deflating the book value of capital by the fixed asset price index, and the unit is 10,000 yuan. In terms of output indicators, we estimate the carbon dioxide emissions of each city in million tons by the method proposed by the Intergovernmental Panel on Climate Change in 2006. And, the GDP of each city is deflated by the price index of the base year 2000; the unit of measurement is 10,000 yuan, which shows the economic development of the city. Finally, the afforestation area mainly represents the artificial afforestation area of each city, and the unit of measurement is ten thousand hectares. The data are mainly from China's Urban Statistical Yearbook, China's Energy Statistical Yearbook, China's Forestry Statistical Yearbook, and the official websites of statistics bureaus of cities.

If there are $Q$ decision-making units (DMU) and, in every period $t(t=1, \ldots, T)$ and in every DMU, there are $G$ kinds of general input $x=\left(x_{1 t}, \ldots, x_{\mathrm{gt}}\right)$, $U$ kinds of unexpected input $z=\left(z_{1 t}, \ldots, z_{\mathrm{ut}}\right), P$ kinds of expected output $y=\left(y_{1 t}, \ldots, y_{\mathrm{pt}}\right)$, and $S$ kinds of unexpected output $b=\left(b_{1 t}, \ldots, b_{\mathrm{st}}\right)$, then the low-carbon economy producing function is 


$$
T=\left[\left(x_{t}, z_{t}, y_{t}, b_{t}\right) \sum_{j=1}^{J} \lambda_{j s} x_{g j s} \leq x_{g t} \forall g ; \sum_{j=1}^{J} \lambda_{j s} z_{u j s} \geq z_{u t} \forall u ; \sum_{j=1}^{J} \lambda_{j s} \geq y_{p t} \forall p ; \sum_{j=1}^{J} \lambda_{j s} b_{i j s}=b_{i t} \forall i ; \sum_{j=1}^{J} \lambda_{j t}=1 ; \lambda_{i s} \geq 0, j=1,2, \ldots, J\right] .
$$

On the basis of the above functions, the distance from each decision-making unit to the optimal production front is calculated by using the directional distance function. According to Fukuyama and Weber [56], the relaxation measure is introduced into the directional distance function, and the SBM model is established. Based on this, the unexpected input and unexpected output are calculated, and the calculation formula is

$$
\begin{aligned}
\vec{D}^{t}\left(x_{q t}, y_{q t}, b_{q t}, g\right) & =\max \frac{1}{4}\left[\frac{1}{G} \sum_{g=1}^{G} \frac{s_{g t}^{x}}{g_{g t}^{x}}+\frac{1}{U} \sum_{p=1}^{P} \frac{s_{u t}^{x}}{g_{u t}^{x}}+\frac{1}{P} \sum_{p=1}^{P} \frac{s_{p t}^{y}}{g_{p t}^{y}}+\frac{1}{I} \sum_{i=1}^{I} \frac{s_{i t}^{b}}{g_{i t}^{b}}\right] \\
Z_{r k t} & =\sum_{j=1}^{J} \lambda_{j s} z_{r j s}-s_{r t}^{R}, \quad r=1, \ldots, R ; t=1, \ldots, T, \\
y_{m k t} & =\sum_{j=1}^{J} \lambda_{j s} y_{m j s}-s_{m t}^{y}, \quad m=1, \ldots, M ; t=1, \ldots, T, \\
b_{i k t} & =\sum_{j=1}^{J} \lambda_{j s} b_{i j s}-s_{i t}^{b}, \quad i=1, \ldots, I ; t=1, \ldots, T, \\
\forall_{r t} & =1, \ldots, T ; S_{n t}^{x} \geq 0 \text { and } \forall n ; S_{r t}^{x} \geq 0 \text { and } \forall r ; S_{m t}^{y} \geq 0 \text { and } \forall m ; S_{i t}^{b} \geq 0 \text { and } \forall i, \sum_{j=1}^{J} \lambda_{j s}=1 ; \lambda_{j s} \geq 0, \forall j, \text { and } \forall s,
\end{aligned}
$$

where $x_{0}$ represents $G$-dimensional general input, $z_{0}$ represents $U$-dimensional unexpected input, $y_{0}$ represents $P$ dimensional expected output, $b_{0}$ represents $I$-dimensional unexpected output, $\left(g^{x}, g^{z}, g^{y}, g^{b}\right)$ are directional vectors, respectively, indicating the decrease of general input, the increase of unexpected input, the increase of expected output, and the decrease of unexpected output, and $\left(s^{x}, s^{z}, s^{y}, s^{b}\right)$ represents the vectors of general input redundancy, unexpected input shortage, expected output shortage, and unexpected output redundancy. In order to accurately calculate the distance function value, the direction vector is expressed as standardized input and output relaxation variables:

$$
\begin{gathered}
g_{n}^{x}=x_{n}^{\max }-x_{n}^{\min }, \\
g_{r}^{z}=z_{r}^{\max }-z_{r}^{\min }, \\
g_{m}^{y}=y_{m}^{\max }-y_{m}^{\min }, \\
g_{i}^{b}=b_{i}^{\max }-b_{i}^{\min } .
\end{gathered}
$$

In order to avoid the error of calculation result caused by sampling error of DEA in analyzing sample data, bootstrap technology is introduced to measure the urban low-carbon economy situation to improve the accuracy of the results. The basic idea of the bootstrap-DEA model is to apply the resampling technology to the original sample data and calculate a large number of simulated datasets by the DEA model.
Step 1. for each $\operatorname{DMU}_{k}(k=1, \ldots, K)$ in the sample, the original efficiency value $\theta_{k}$ of the DEA model is obtained by solving the linear programming problem of formulas (2) and (3) (the superscript $t$ of time is omitted to avoid the tedious)

Step 2. generating random samples with length $K$ based on smooth bootstrap sampling, which is shown as $\left\{\theta_{i} ; i=1,2, \ldots, k\right\}$

Step 3. according to the results of the previous step, a pseudodataset is generated $\left\{\left(x_{i}^{*}, y_{i}, b_{i}^{*}\right)\right\}, i=1,2, \ldots, k$, $x_{i}^{+}=\left(\theta_{k} / \theta_{i}^{*}\right)_{i}^{x}$, and $u_{i}^{*}=\left(\theta_{k} / \theta_{i}^{*}\right) u_{i}$, which constitutes the reference set in the bootstrap-DEA model

Step 4. the estimated value $\theta_{k}^{*}$ of bootstrap of $\theta_{k}$ is obtained by solving equation (3) from the pseudodataset

Step 5. repeat Step 2 to Step 4 for 2,000 times to obtain a series of estimated values $\left\{\theta_{k b}^{*} ; b=1,2, \ldots, B\right\}$ of the original efficiency value $\widehat{\theta}_{k}$

Bootstrap estimators obtained based on the above iterative process can simulate the distribution of the original efficiency estimators and then correct the bootstrap deviation of the DEA model. The error of $L$ can be calculated by the following formula: 


$$
\operatorname{Bias}\left(\theta_{k}\right)=\bar{\theta}_{k}^{*}-\theta_{k}, \bar{\theta}_{k}^{*}=B^{-1} \sum_{b=1}^{B} \theta_{k b}^{*}
$$

The estimated low-carbon total factor efficiency of the global DEA model after bootstrap rectification is

$$
\tilde{\theta}_{k}=\theta_{k}-\operatorname{Bias}\left(\theta_{k}\right)=2 \theta_{k}-B^{-1} \sum_{b=1}^{B} \theta_{k b}^{*}
$$

3.2. Econometric Strategy. The DID method was employed to study the effect of smart city policy on low-carbon economy. This may be described by

$$
\mathrm{ML}_{i t}=a_{0}+a_{1}\left(d u_{i t} * d t_{i t}\right)+a_{2} d u_{i t}+a_{3} d t_{i t}+\lambda x_{i t}+\mu_{i t},
$$

where $i$ represents the sample, $t$ means the time, $\mathrm{ML}_{i t}$ represents the total factor production efficiency of lowcarbon economy of city $i$ at time $t, \mathrm{du}_{i t}$ represents the dummy variables of the experimental group and control group, $\mathrm{du}_{i t}=1$ means that the sample belongs to the experimental group, $\mathrm{du}_{i t}=0$ means that the sample belongs to the control group, $\mathrm{dt}_{i t}$ represents the time dummy variable, $\mathrm{dt}_{i t}=1$ indicates that the smart city pilot policy has been implemented in $t$ period, $\mathrm{dt}_{i t}=0$ indicates that the smart city pilot policy has not been implemented in $t$ period, $x_{i t}$ is the control variable, and $\mu_{i t}$ is the random disturbance term.

Equation (7) expresses the average impact of implementing smart city policy on low-carbon economy. And, the regression model is shown in the following equation to determine the dynamic effect of smart city on low-carbon economy:

$$
\mathrm{ML}_{i t}=a_{0}+\sum_{t=2013}^{2018} a_{1}\left(\mathrm{du}_{i t} * \mathrm{dt}_{i t}\right)+a_{2} \mathrm{du}_{i t}+a_{3} \mathrm{dt}_{i t}+\lambda x_{i t}+\mu_{i t} .
$$

Referring to $[57,58]$, a series of control variables will be considered: technological innovation (Innov) is measured by the number of patents granted by $G$ (computer and automation equipment) and $H$ (semiconductor and communication technology), which belong to ICP classification number and the total number of patents granted by cities. The industrial structure (Indus) is measured by the proportion of the tertiary industry in GDP. Government scale (GScale) is measured by the proportion of government budget expenditure in GDP. The degree of opening up (Open) is measured by the proportion of FDI in GDP. Information technology facilities (Infra) are expressed by the proportion of Internet users in the total urban population. The scale of the city (Size) is measured by the population at the end of the year (unit: 10,000 people), and the financial development level (Fin) is measured by the proportion of the total deposits and loans of financial institutions in GDP at the end of the year. Human capital (Human) is calculated by the proportion of university and college students in the total population. Average economic development (Pgdp) is measured by GDP per unit of capital. Table 1 shows the variable definitions and their measurement.

3.3. Data. Following the principle of representatives and continuity of data, our sample consists of a panel data of prefecture level 230 cities from 2005 to 2018. Our data come from official sources, such as China Statistical Yearbook, China Urban Statistical Yearbook, China Regional Economic Statistical Yearbook, China Urban Construction Statistical Yearbook, China Fixed Assets Investment Yearbook, China Forestry Statistical Yearbook, China Environment Statistical Yearbook, and China Energy Statistical Yearbook. It should be noted that we have processed the sample as follows: (1) due to the lack of data, the data from Tibet, Hong Kong, Macao, and Taiwan are not included. (2) The sample cities with only one county or district as the pilot are excluded from the sample. Table 2 shows the descriptive statistics of the results.

\section{Results and Discussion}

4.1. Estimated Low-Carbon Total Factor Productivity. In order to understand the dynamic evolution of China's lowcarbon economy from 2005 to 2018, the kernel density function analysis technology is introduced for evaluation, which depicts the dynamic evolution of low-carbon economy in different periods, as shown in Figures 4(a)-4(c). We can see that, firstly, during the observation period, the center of the kernel density function of all cities moves to the right, and the peak value and curve shape of the function also change to some extent. In addition, the polarization phenomenon has also experienced different changes, indicating that the low-carbon total factor productivity increases with the passage of time, and the regional difference is not short. The right tail of the low-carbon economy kernel density function curve of all cities gradually disappeared, indicating that the implementation of SCP has promoted the development of low-carbon economy in pilot cities. The multipeak shape of the urban kernel density curve in the eastern region is more and more obvious, indicating that there is a weak multilevel differentiation in the region. The height of the main peak of urban kernel density curve in Central and Western China increased significantly at first and then decreased gradually, while the change range of kernel density center was weak, indicating that the low-carbon efficiency had little change, and the difference between provinces was obvious.

4.2. Effects of SCP on Low-Carbon Economy. The calculation results of OLS formula (6) are shown in Table 3. The first column is the result without control variables, and the second to tenth columns are the calculation results with control variables. From the regression results, we can see that whether the control variables are considered or not; $\mathrm{du} \times \mathrm{dt}$ has a positive impact on the development of China's low-carbon economy. This is an attribute to the advancement of smart city construction that promotes the gradual development of new technologies and industries, the 
TABle 1: Variable definitions and measurement.

\begin{tabular}{|c|c|c|}
\hline Variable & Definition & Measurement \\
\hline MLit & $\begin{array}{l}\text { Low-carbon total factor } \\
\text { productivity }\end{array}$ & $\begin{array}{c}\text { Calculated by bootstrap-DEA model; input: capital, labor, and energy; desired output: real GDP } \\
\text { and afforestation area; undesired output: carbon emissions }\end{array}$ \\
\hline Innov & Technology innovation & $\begin{array}{c}\text { Calculated by the proportion of patents granted by } G \text { and } H \text { in the total city patents to acquire } \\
\text { technology innovation level }\end{array}$ \\
\hline Indus & The industrial structure & Measured by the proportion of the tertiary industry in GDP \\
\hline & & Measured by the proportion of government budget expenditure in GDP \\
\hline Open & The level of op & Measured by the proportion of FDI in GDP \\
\hline Infra & Information & Measured by the pro \\
\hline Size & Urban scale & lation \\
\hline Fin & Financial development & $\begin{array}{c}\text { Measured by the proportion of the total deposits and loans of financial institutions in GDP at the } \\
\text { end of the year }\end{array}$ \\
\hline Human & & Calculated by the proportion of university and college students in the total population \\
\hline Pgdp & $\begin{array}{l}\text { The level of economy } \\
\text { development }\end{array}$ & Measured by GDP per unit of capital \\
\hline
\end{tabular}

TABle 2: Descriptive statistics of the various variables for the different groups.

\begin{tabular}{|c|c|c|c|c|c|c|c|c|c|}
\hline \multirow{2}{*}{ Variable } & \multicolumn{3}{|c|}{ Total sample } & \multicolumn{3}{|c|}{ Control group $(\mathrm{du}=0)$} & \multicolumn{3}{|c|}{ Treatment group $(\mathrm{du}=1)$} \\
\hline & Obs. & Mean & Std. dev. & Obs. & Mean & Std. dev. & Obs. & Mean & Std. dev. \\
\hline MLit & 3220 & 1.0263 & 0.5032 & 2100 & 0.9653 & 0.2103 & 1120 & 1.3359 & 0.2055 \\
\hline Innov & 3220 & 0.0897 & 0.1289 & 2100 & 0.0680 & 0.0412 & 1120 & 0.1387 & 0.5263 \\
\hline Indus & 3220 & 0.4331 & 0.2252 & 2100 & 0.4130 & 0.1109 & 1120 & 0.4934 & 0.0786 \\
\hline GScale & 3220 & 0.1493 & 0.0692 & 2100 & 0.1822 & 0.0853 & 1120 & 0.1477 & 0.0692 \\
\hline Open & 3220 & 0.1369 & 0.1036 & 2100 & 0.1232 & 0.1206 & 1120 & 0.1459 & 0.1341 \\
\hline Infra & 3220 & 0.1231 & 0.1502 & 2100 & 0.1041 & 0.0558 & 1120 & 0.1439 & 0.0522 \\
\hline Size & 3220 & 2.8564 & 0.2201 & 2100 & 2.8620 & 0.1102 & 1120 & 2.8437 & 0.2603 \\
\hline Fin & 3220 & 0.3622 & 0.2256 & 2100 & 0.3682 & 0.2741 & 1120 & 0.3598 & 0.1743 \\
\hline Human & 3220 & 0.0254 & 0.0631 & 2100 & 0.0087 & 0.0149 & 1120 & 0.0034 & 0.0065 \\
\hline Pgdp & 3220 & 10.3371 & 0.6570 & 2100 & 10.047 & 0.5203 & 1120 & 10.409 & 0.5012 \\
\hline
\end{tabular}

continuous improvement of information infrastructure, and the popularization of terminal smart application. Undoubtedly, the technological effect, industrial structure upgrading effect, and resource allocation effect induced by smart city construction have been effectively brought into play, so the impact of smart city policy on the low-carbon economy is increasingly strengthened. More specifically, without control variables, the SCP has improved the lowcarbon economy by about $5.9 \%$ and considering all control variables by around $4.5 \%$.

When considering the nine control variables step by step, only Innov, Indus, human resources, and Pgdp have significant positive effects on low-carbon economy, and their coefficients are all positive. Technological innovation promotes the optimization of the industrial structure, the development of tertiary industry promotes the operation of low-carbon economy, and the development of Pgdp promotes the economic agglomeration effect, thus restraining carbon emissions. The coefficient of government scale, opening degree, and city scale is negative, which shows that the increase of government budget expenditure is not conducive to the development of low-carbon economy. Foreign investment may bring some enterprises with high carbon emissions. The expansion of the city scale is accompanied by the aging of population and the reduction of family size, which are not conducive to the development of low-carbon economy.
4.3. Test Based on PSM-DID Method. Due to the different development level of low-carbon economy between SCP pilot cities and nonpilot cities, this paper uses PSM-DID (propensity score matching-difference in difference) method to test the robustness to reduce the possible deviation of the results of DID. First, we need to test the balance of the model, and the test results are shown in Table 4. After matching, the standardized deviation of all variables is less than $10 \%$, which has a good balance effect. Secondly, from the point of view of the $p$ value, there is no systematic difference between the experimental group and control group. It shows that PSM results are effective, and this robustness test method is more suitable for analyzing the impact of SCP on low-carbon economy.

The empirical results based on the PSM-DID method are summarized in Table 5. The results show that smart city construction significantly improves the urban low-carbon economy by $5.3 \%$. That is to say, there is no significant difference between the estimation results based on the PSMDID method and the aforementioned DID results, which further supports the robustness of the empirical conclusions in this paper.

4.4. Robustness Test. In order to ensure that the result is robust, we carry out a series of robustness tests, which includes the placebo test, parallel trend hypothesis test, and 


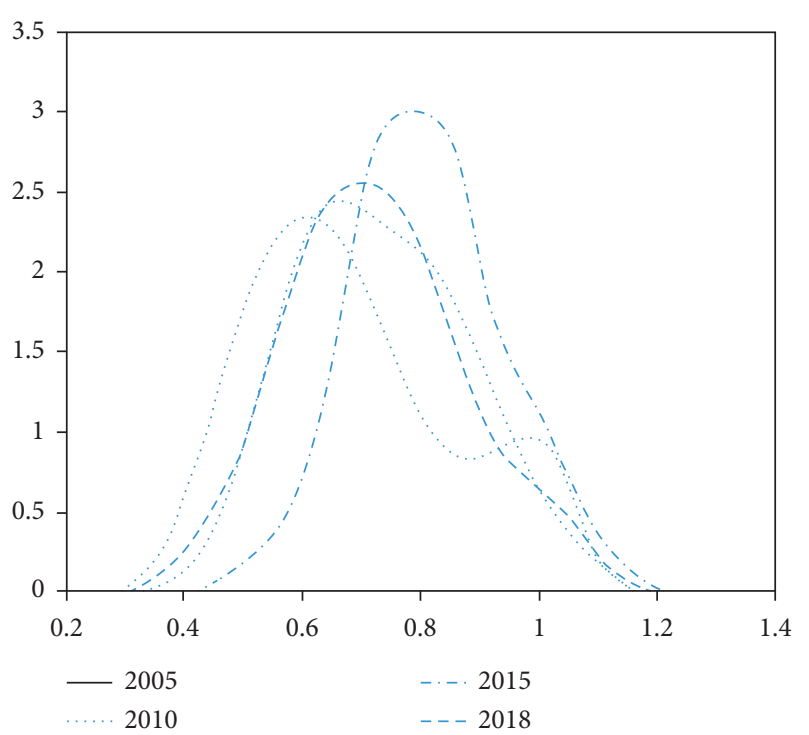

(a)

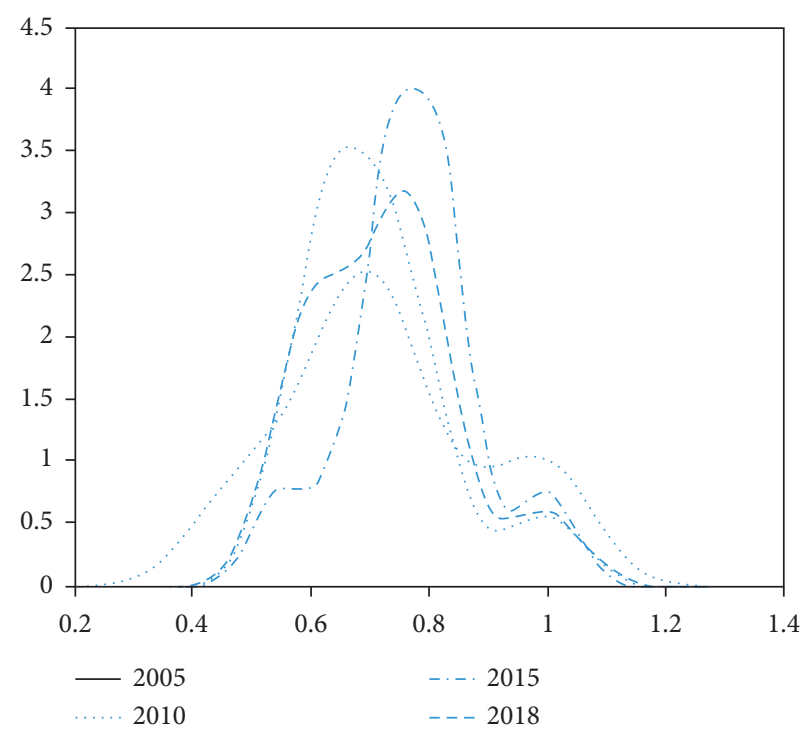

(b)

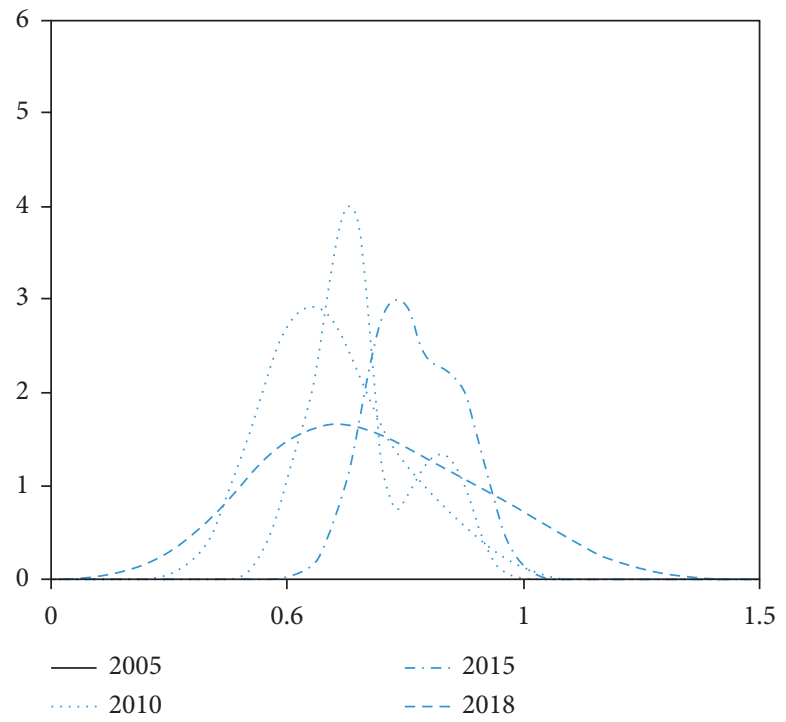

(c)

FIgURE 4: The kernel density curve of the study samples. (a) All. (b) Eastern region. (c) Central and western.

dynamic effect analysis and changing the window width before and after the SCP policy.

4.4.1. Placebo Test. In order to further verify that the conclusion of this paper does not miss a series of other not observable driving factors, referring to the research of Cai et al. [59], we randomly selected cities from the sample to test the main results of this paper with a placebo test. And, 80 cities of the total sample were selected randomly as the artificial treatment group, and the remaining cities as the artificial control group. At the same time, we set a dummy variable $\mathrm{du}_{c}^{\text {false }}$ and a placebo cross term $\mathrm{du}_{c}^{\text {false }} \times \mathrm{du}_{t}$, which should not have a significant impact on the explained variable and $\beta^{\text {false }}=0$ because the treatment group is artificial. That is to say, if there is no significant missing variable deviation, the regression coefficient of the placebo-treated variables will not deviate significantly from 0 . If the estimation coefficient of $\beta^{\text {false }}$ deviates significantly from 0 statistically, it means that there is recognition error in the model setting, that is, other factors that promote the development of low-carbon economy are omitted. Additionally, in order to avoid the interference of other small probability events on the estimation results, we repeated the above process for regression analysis 200 times. Figure 5 reports the estimated coefficient kernel density and corresponding $p$ value distribution of 200 randomly generated processing groups. We can see that the mean value of the regression system is very close to 0 , and most $p$ values are greater than 0.1, which proves that the estimation results in this paper are not missing other important variables which may cause serious errors. 
TABLE 3: Estimation results of panel OLS with dependent variable MLit.

\begin{tabular}{|c|c|c|c|c|c|c|c|c|c|c|}
\hline Variable & (1) & $(2)$ & (3) & (4) & (5) & (6) & $(7)$ & (8) & (9) & $(10)$ \\
\hline $\mathrm{du} \times \mathrm{dt}$ & $\begin{array}{c}0.0587^{* * *} \\
(3.9685)\end{array}$ & $\begin{array}{c}0.0532^{* * *} \\
(3.8701)\end{array}$ & $\begin{array}{c}0.0528^{* * *} \\
(3.8659)\end{array}$ & $\begin{array}{c}0.0523^{* * *} \\
(3.8612)\end{array}$ & $\begin{array}{c}0.0514^{* * *} \\
(3.8022)\end{array}$ & $\begin{array}{c}0.0506^{* * *} \\
(3.7904)\end{array}$ & $\begin{array}{c}0.0501^{* * *} \\
(3.7885)\end{array}$ & $\begin{array}{c}0.0463^{* * *} \\
(3.6515)\end{array}$ & $\begin{array}{c}0.0426^{* * *} \\
(3.3604)\end{array}$ & $\begin{array}{c}0.0449^{* * *} \\
(3.3517)\end{array}$ \\
\hline Innov & & $\begin{array}{c}0.0352^{* * *} \\
(3.1453)\end{array}$ & $\begin{array}{c}0.0347^{* * *} \\
(3.1408)\end{array}$ & $\begin{array}{c}0.0322^{* * *} \\
(3.1247)\end{array}$ & $\begin{array}{c}0.0298^{* * *} \\
(3.0052)\end{array}$ & $\begin{array}{c}0.0287^{* * *} \\
(2.9837)\end{array}$ & $\begin{array}{c}0.0274^{* * *} \\
(2.8979)\end{array}$ & $\begin{array}{c}0.0263^{* * *} \\
(2.8928)\end{array}$ & $\begin{array}{c}0.0259^{* * *} \\
(2.8901)\end{array}$ & $\begin{array}{c}0.0241^{* * *} \\
(2.8857)\end{array}$ \\
\hline Indus & & & $\begin{array}{c}0.0209^{* * *} \\
(3.7221)\end{array}$ & $\begin{array}{c}0.0207^{* * *} \\
(3.7044)\end{array}$ & $\begin{array}{c}0.0204^{* * *} \\
(3.6858)\end{array}$ & $\begin{array}{c}0.0199^{* * *} \\
(3.6629)\end{array}$ & $\begin{array}{c}0.0187^{* * *} \\
(3.6436)\end{array}$ & $\begin{array}{c}0.0182^{* * *} \\
(3.5104)\end{array}$ & $\begin{array}{c}0.0176^{* * *} \\
(3.4002)\end{array}$ & $\begin{array}{c}0.0175^{* * *} \\
(3.3917)\end{array}$ \\
\hline GScale & & & & $\begin{array}{c}-0.0895^{* *} \\
(-1.3987)\end{array}$ & $\begin{array}{l}-0.0916^{* *} \\
(-1.4054)\end{array}$ & $\begin{array}{c}-0.0832^{* *} \\
(-1.2541)\end{array}$ & $\begin{array}{l}-0.0952^{* *} \\
(-1.4497)\end{array}$ & $\begin{array}{l}-0.0809^{* *} \\
(-1.3905)\end{array}$ & $\begin{array}{l}-0.0794^{* *} \\
(-1.3842)\end{array}$ & $\begin{array}{c}-0.0953^{* *} \\
(-1.4836)\end{array}$ \\
\hline Open & & & & & $\begin{array}{l}-0.0925^{*} \\
(-1.2162)\end{array}$ & & & & & $\begin{array}{l}-0.0914^{*} \\
(-1.2185)\end{array}$ \\
\hline Infra & & & & & & $\begin{array}{l}0.0092^{*} \\
(0.9966)\end{array}$ & $\begin{array}{l}0.0083^{*} \\
(0.9902)\end{array}$ & $\begin{array}{l}0.0065^{*} \\
(0.9749)\end{array}$ & $\begin{array}{l}0.0041^{*} \\
(0.9682)\end{array}$ & $\begin{array}{l}0.0037^{*} \\
(0.9663)\end{array}$ \\
\hline Size & & & & & & & $\begin{array}{l}-0.0223^{*} \\
(-1.0132)\end{array}$ & $\begin{array}{c}-0.0207^{*} \\
(-1.004)\end{array}$ & $\begin{array}{l}-0.0199^{*} \\
(-0.9865)\end{array}$ & $\begin{array}{l}-0.0184^{*} \\
(-0.9833)\end{array}$ \\
\hline Fin & & & & & & & & & & \\
\hline Human & & & & & & & & & $\begin{array}{c}0.0105^{* * *} \\
(1.7306)\end{array}$ & $\begin{array}{c}0.0103^{* * *} \\
(1.7299)\end{array}$ \\
\hline Pgdp & & & & & & & & & & $\begin{array}{c}0.0196^{* * *} \\
(3.4408)\end{array}$ \\
\hline Constant & $\begin{array}{l}0.5239^{* * *} \\
(49.2013)\end{array}$ & $\begin{array}{l}0.4887^{* * *} \\
(47.6791)\end{array}$ & $\begin{array}{l}0.5031^{* * *} \\
(43.2241)\end{array}$ & $\begin{array}{l}0.5540^{* * *} \\
(34.0670)\end{array}$ & $\begin{array}{l}0.5306^{* * *} \\
(29.6502)\end{array}$ & $\begin{array}{l}0.5412^{* * *} \\
(25.9688)\end{array}$ & $\begin{array}{l}0.6203^{* * *} \\
(19.4347)\end{array}$ & $\begin{array}{c}0.6395^{* * *} \\
(16.0203)\end{array}$ & $\begin{array}{c}0.6802^{* * *} \\
(14.0702)\end{array}$ & $\begin{array}{c}0.6703^{* * *} \\
(13.9026)\end{array}$ \\
\hline Observations & 3220 & 3220 & 3220 & 3220 & 3220 & 3220 & 3220 & 3220 & 3220 & 3220 \\
\hline$R$-squared & 0.0955 & 0.1123 & 0.1137 & 0.1164 & 0.1291 & 0.1330 & 1.1348 & 1.1365 & 1.1397 & 1.1406 \\
\hline
\end{tabular}

Notes: (1) robust $t$-statistics in parentheses; $(2){ }^{* * *} p<0.01,{ }^{* *} p<0.05$, and ${ }^{*} p<0.1$.

TABLE 4: PSM matching effect test: balance test of all variables before and after matching.

\begin{tabular}{lcccc}
\hline Variables & Treatment group mean & Control group mean & Mean bias $(\%)$ & $p$ value \\
\hline MLit & 1.1208 & 1.1146 & 1.3 & 3.2 \\
Innov & 0.1271 & 0.0959 & 7.4 & $\leq 0.001$ \\
Indus & 0.4873 & 0.4607 & -1.6 & $\leq 0.001$ \\
GScale & 0.1465 & 0.1488 & 5.7 & $\leq 0.001$ \\
Open & 0.1404 & 0.1353 & 2.1 & $\leq 0.001$ \\
Infra & 0.1396 & 0.1375 & -1.8 & $\leq 0.001$ \\
Size & 2.8401 & 2.8542 & -1.5 & $\leq 0.001$ \\
Fin & 0.3522 & 0.3611 & -1.9 & $\leq 0.001$ \\
Human & 0.0207 & 0.0260 & 3 & $\leq 0.001$ \\
Pgdp & 10.382 & 10.356 & $\leq 0.001$ \\
\hline
\end{tabular}

Notes: $(1){ }^{* * *},{ }^{* *}$, and ${ }^{*}$ denote significance at the $1 \%, 5 \%$, and $10 \%$ levels, respectively; (2) the null hypothesis is that there is no significant difference between the treatment group and the control group.

TABLE 5: Smart city construction and low-carbon economy: PSM-DID robustness test.

\begin{tabular}{lccc}
\hline & & MLit & \\
& Before policy implementation & After policy implementation & DID result \\
\hline Treatment group & -0.432 & -0.475 \\
Control group & -0.398 & -0.494 & 0.053 \\
Diff $(T-C)$ & -0.034 & 0.019 & 0.030 \\
$S$. err. & 0.054 & 0.051 & 1.851 \\
$T$ value & -1.320 & 0.682 & $0.088^{*}$ \\
$p$ value & 0.1251 & 0.3976 & \\
\hline
\end{tabular}

4.4.2. Parallel Trend Hypothesis Test and Dynamic Effect. Considering that economic development is a dynamic process, it is necessary to further study the dynamic marginal effect of smart city pilot policy on China's low-carbon economic development. The premise of this study is that the trend of low-carbon economy development in the treatment group and the control group should be consistent before the smart city pilot policy takes place. With the implement of the pilot policy of smart city, the difference between the treatment group and the control group should begin to increase. Based on the research methods of Liu and Qiu [60], we further investigate the change trend of the treatment 


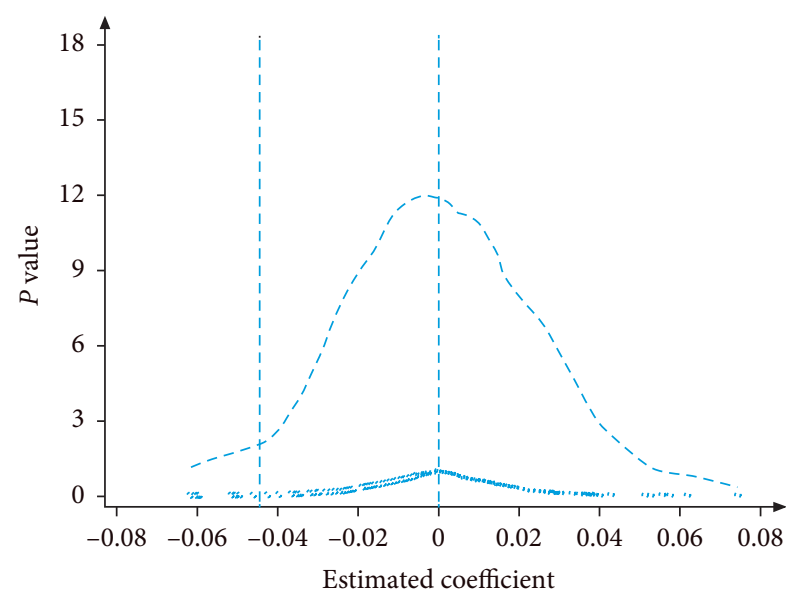

FIgUre 5: The result of the placebo test.

group and the control group. The empirical equation is set as follows:

$$
y_{\mathrm{pt}}=\theta_{k} \sum_{k \geq-5}^{6+} \mathrm{du}_{p} * \mathrm{dt}_{2012+k}+X_{\mathrm{pt}} \delta+a_{p}+\partial_{t}+\gamma_{\mathrm{pt}} .
$$

Among them, $\mathrm{dt}$ is the annual dummy variable, the observation value of the current year is 1 , and the observation value of other years is 0 . Other variables are consistent with the benchmark model. We tested the trend change from five years before the smart city policy pilot in 2012 to the last year of the sample. Figure 6 reports the results of the analysis. It shows the results of the $90 \%$ confidence interval of the regression coefficient of each year, and the dotted line shows the marginal effect of the dual interaction term on the development of China's low-carbon economy. We can see that, before 2012, the coefficient of the double interaction term basically fluctuated around 0 which was not significant, and the trend of the treatment group and control group is consistent. After 2012, the marginal effect line rapidly inclines to the upper right, and the impact effect shows an increasing trend, which indicates that the smart city pilot policy has a significant positive impact on the low-carbon economy, and the impact effect is becoming stronger and stronger.

4.4.3. Changing the Window Width Test. We try to change the window width before and after the SCP to test the different results spanning different periods. At the same time, this method also could help us to know about how the sensitivity of smart city construction to time changes. Specifically, this paper uses the pilot time of SCP in 2012 as the time node and chooses 1 year, 2 years, 3 years, 4 years, and 5 years as window width to carry out logical regression, respectively. The coefficients added to the logic regression have not changed significantly, so the results are robust, and the regression results are shown in Table 6. It can be seen from Table 7 that the system estimated in different time window widths is still significantly positive, indicating that SCP has promoted the development of low-carbon economy. Then, with the increase of the width of the window, the coefficient decreases, indicating that the low-carbon

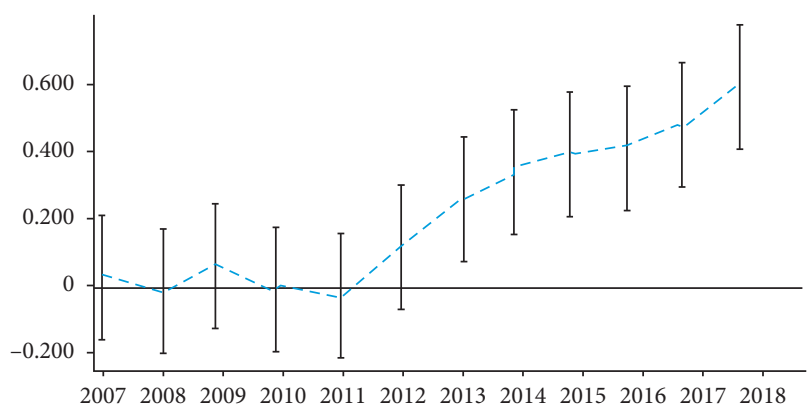

FIgure 6: Dynamic effects of SCP on LCE in China.

economic development is not significant before the implementation of SCP.

4.5. Heterogeneity Analysis. In order to measure and understand the heterogeneity of SCP for LCE, we will analyze the heterogeneity of sample data from three aspects. And, these three aspects are the heterogeneity of the geographical location, the heterogeneity of urban population size, and the heterogeneity of environmental regulation.

Firstly, there are great differences in the level of economic development in China, which is reflected in geographical locations, and economic development levels in different regions lead to differences in smart city development strategies. Therefore, this study will separately discuss the impact of SCP in different regions on low-carbon economy, and we divide the sample in different regional categories: (1) cities are classified as the eastern, central, and western regions, while the level of economic development is the best in the eastern region, followed by the central region and the worst in the western region. (2) Cities are divided into coastal cities and noncoastal cities, and the former have better economic development than the latter.

Secondly, we group cities according to the size of cities. According to the notice of the State Council of the People's Republic of China on adjusting the standard of city size classification, we divide the samples into three categories: small-, medium-, and large-scale cities. Finally, they are classified by whether the strict degree of environmental protection regulation and planning are implemented. Referring to the information of China Environmental Yearbook, municipal governments, provincial capitals, core tourist cities, and coastal open cities are the key cities of environmental protection, with strict environmental protection planning (KEP). These cities are the key cities to control and prevent carbon emissions. Other cities are nonKEP.

The estimates are summarized in Tables 6 and 8. The coefficients of $\mathrm{du} \times \mathrm{dt}$ are positively associated with LCE across different groups, indicating that the SCP can also effectively improve LCE by considering regional heterogeneity. From Table 7, we can see that the impact of SCP on LCE is weaker in eastern regions with the better economic development level than in central and western regions with the lower economic development level. Meanwhile, the influence of noncoastal cities is stronger than that of coastal 
TABLE 6: Effect of the SCP on the LCE: geographical heterogeneity.

\begin{tabular}{lccccc}
\hline Variable & $(1)$ & $(2)$ & $(3)$ & $(4)$ & $(5)$ \\
Castern & Central & Western & Coastal & Noncoastal \\
\hline du $\times \mathrm{dt}$ & $0.0339^{*}(1.3209)$ & $0.0517^{* * *}(3.2085)$ & $0.0545^{* * *}(1.8869)$ & $0.0393^{*}(1.0062)$ & $0.0484^{* * *}(2.0694)$ \\
Innov & $0.0122^{*}(3.2872)$ & $0.0338^{* *}(3.2296)$ & $0.0397^{* * *}(2.4017)$ & $0.0115^{*}(1.0205)$ & $0.0351^{* *}(1.6914)$ \\
Indus & $0.0298^{* *}(3.4128)$ & $0.0315^{* *}(2.8266)$ & $0.0335^{* *}(3.7961)$ & $0.0147^{* *}(1.0834)$ & $0.0288^{* *}(1.5501)$ \\
GScale & $-0.0688^{*}(-1.3040)$ & $-0.5027^{*}(-1.5834)$ & $-0.0379^{*}(-1.2582)$ & $-0.0307^{*}(-1.3798)$ & $-0.0352^{*}(-1.5021)$ \\
Open & $-0.0854^{* *}(-1.3292)$ & $-0.0912^{* *}(-1.8041)$ & $-0.0908^{* *}(-1.3377)$ & $-0.0811^{*}(-0.5896)$ & $-0.0917^{*}(-1.2449)$ \\
Infra & $0.0022^{*}(1.9073)$ & $0.0069^{*}(1.6502)$ & $0.0051^{*}(0.9785)$ & $0.0033^{*}(0.8115)$ & $0.0035^{*}(1.8341)$ \\
Size & $-0.0202^{*}(-1.2869)$ & $-0.0255^{*}(-1.1967)$ & $-0.0354^{*}(-0.5802)$ & $-0.0229^{*}(-1.9003)$ & $-0.0207^{*}(-1.5417)$ \\
Fin & $0.0056^{*}(1.3308)$ & $0.0063^{*}(1.8596)$ & $0.0082^{*}(1.5507)$ & $0.0058^{*}(1.3939)$ & $0.0064^{*}(1.2804)$ \\
Human & $0.0102^{* * *}(1.0824)$ & $0.0259^{* * *}(1.1037)$ & $0.0398^{* * *}(0.8597)$ & $0.0104^{* * *}(1.0201)$ & $0.0357^{* * *}(1.3970)$ \\
Pgdp & $0.0122^{* * *}(1.3025)$ & $0.0159^{* * *}(1.2887)$ & $0.0308^{* * *}(1.5697)$ & $0.0128^{* * *}(1.1214)$ & $0.0207^{* * *}(1.4590)$ \\
Constant & $0.4697^{* * *}(23.332)$ & $0.4855^{* *}(39.578)$ & $0.4704^{* * *}(41.056)$ & $0.4983^{* * *}(33.978)$ & $0.4782^{* * *}(26.308)$ \\
Observations & 1540 & 1330 & 350 & 1204 & 2016 \\
$R$-squared & 0.0997 & 0.0798 & 0.0115 & 0.0712 & 0.0873 \\
\hline
\end{tabular}

Notes: (1) robust $t$-statistics in parentheses; $(2){ }^{* * *} p<0.01,{ }^{* *} p<0.05$, and ${ }^{*} p<0.1$.

TABLE 7: Regression results for changing time window width.

\begin{tabular}{lccccc}
\hline Variables & $T 1$ & $T 2$ & $T 3$ & $T 4$ & $T$ \\
& $2011-2013$ & $2010-2013$ & $2009-2015$ & $2008-2016$ & $2007-2017$ \\
\hline $\mathrm{du} \times \mathrm{dt}$ & $0.0607^{* * *}(4.1213$ & $0.0598^{* * *}(5.0227)$ & $0.0575^{* * *}(5.4094)$ & $0.0492^{* * *}(5.8730)$ & $0.0446^{* * *}(5.0024)$ \\
Innov & $0.0258^{* * *}(4.3671)$ & $0.0249^{* * *}(9.3471)$ & $0.0289^{* * *}(5.2296)$ & $0.0357^{* * *}(4.0024)$ & $0.0387^{* * *}(5.3182)$ \\
Indus & $0.0362^{* * *}(3.5174)$ & $0.0058^{* *}(6.6502)$ & $0.0044^{* *}(5.5735)$ & $0.0019^{*}(2.2064)$ & $0.0013^{* *}(2.1730)$ \\
GScale & $-0.0703^{* *}(-1.2409)$ & $-0.0058^{*}(-3.220)$ & $-0.0003^{*}(-15.20)$ & $-0.0001(-22.36)$ & $-0.0069^{*}(-2.361)$ \\
Open & $-0.0795^{*}(-1.0226)$ & $-0.0965^{*}(-0.8564)$ & $-0.0897^{*}(-0.3028)$ & $-0.0402^{*}(-0.1514)$ & $-0.0854^{*}(-0.3075)$ \\
Infra & $0.0013^{*}(1.4534)$ & $0.0009^{*}(2.2208)$ & $0.0022^{*}(5.2094)$ & $0.0008(10.021)$ & $0.0003(15.026)$ \\
Size & $-0.0185^{*}(-1.2230)$ & $-0.0231^{*}(-1.9632)$ & $-0.0556^{*}(-3.0294)$ & $-0.0482^{*}(-2.958)$ & $-0.0703^{*}(-1.1543)$ \\
Fin & $0.0037^{*}(1.6654)$ & $0.0008(4.0302)$ & $0.0054^{*}(1.9064)$ & $0.0026(4.5236)$ & $0.0094^{*}(3.5294)$ \\
Human & $0.0472^{* * *}(1.6053)$ & $0.0563^{* * *}(2.0301)$ & $0.0798^{* *}(11.025)$ & $0.0013^{*}(3.2093)$ & $0.0634^{* *}(5.9210)$ \\
Pgdp & $0.0096^{* * *}(1.9879)$ & $0.0088^{* * *}(2.1543)$ & $0.0075^{* * *}(3.0225)$ & $0.0049^{* * *}(0.0364)$ & $0.0027^{* * *}(2.2052)$ \\
Constant & $0.9665(11.927)$ & $0.4702^{* * *}(9.326)$ & $0.4885^{* * *}(8.110)$ & $0.4926^{* * *}(14.038)$ & $0.4804^{* * *}(15.602)$ \\
$R$-squared & 0.9631 & 0.9867 & 1.1460 & 1.5523 & 1.6942 \\
\hline
\end{tabular}

Notes: (1) robust $t$-statistics in parentheses; $(2){ }^{* * *} p<0.01,{ }^{* *} p<0.05$, and ${ }^{*} p<0.1$.

TABLE 8: Effect of the SCP on the low-carbon economy: heterogeneity.

\begin{tabular}{|c|c|c|c|c|c|}
\hline Variable & $\begin{array}{c}(3) \\
\text { Small }\end{array}$ & $\begin{array}{c}(4) \\
\text { Medium }\end{array}$ & $\begin{array}{c}(5) \\
\text { Large }\end{array}$ & $\begin{array}{c}(6) \\
\text { KEP }\end{array}$ & $\begin{array}{c}(7) \\
\text { Non-KEP }\end{array}$ \\
\hline $\mathrm{du} \times \mathrm{dt}$ & $0.0409^{*}(1.9102)$ & $0.0168(1.0254)$ & $0.0499^{* * *}(3.0459)$ & $0.0231(1.0021)$ & $0.0473^{* * *}(3.6004)$ \\
\hline Innov & $0.0305^{* * *}(2.4017)$ & $0.0018^{* *}(1.0205)$ & $0.0306^{* * *}(3.6914)$ & $0.0258^{* * *}(3.0214)$ & $0.0296^{* * *}(2.8551)$ \\
\hline Indus & $0.0801^{* * *}(3.7961)$ & $0.0025^{* *}(1.0834)$ & $0.0357^{* * *}(3.9306)$ & $0.0121^{* * *}(3.5023)$ & $0.0163^{* * *}(3.9013)$ \\
\hline GScale & $-0.0250^{* *}(-1.0609)$ & $-0.0353^{* *}(-1.4170)$ & $-0.0987^{* *}(-1.3552)$ & $-0.0550^{* *}(-1.1213)$ & $-0.0998^{* *}(-2.0231)$ \\
\hline Open & $-0.0963^{* *}(-1.4701)$ & $-0.0823^{*}(-0.9173)$ & $-0.0905^{*}(-1.3860)$ & $-0.0955^{*}(-1.1402)$ & $-0.0983^{*}(-1.1913)$ \\
\hline Infra & $0.0099^{*}(0.9021)$ & $0.0012 *(0.8832)$ & $0.0020^{*}(1.9069)$ & $0.0085^{*}(0.9092)$ & $0.0091 *(0.9991)$ \\
\hline Size & $-0.0322^{*}(-0.9916)$ & $-0.0278^{*}(-1.4470)$ & $-0.0299^{*}(-1.0930)$ & $-0.0210^{*}(-1.1105)$ & $-0.0204^{*}(-1.0497)$ \\
\hline Fin & $0.0096^{*}(1.2037)$ & $0.0028^{*}(1.5046)$ & $0.0075^{*}(1.7853)$ & $0.0032^{*}(1.4607)$ & $0.0091^{*}(1.7741)$ \\
\hline Human & $0.0332^{* * *}(0.9996)$ & $0.0101^{* * *}(1.0286)$ & $0.0366^{* * *}(1.4352)$ & $0.0204^{* * *}(1.2520)$ & $0.0308^{* * *}(1.4931)$ \\
\hline Pgdp & $0.0235^{* * *}(1.5861)$ & $0.0140^{* * *}(1.0032)$ & $0.0101^{* * *}(1.4970)$ & $0.0123^{* * *}(1.5021)$ & $0.0107^{* * *}(1.3248)$ \\
\hline Constant & $0.4921^{* * *}(43.597)$ & $0.5384^{* * *}(34.112)$ & $0.5209^{* * *}(28.225)$ & $0.3705^{* * *}(19.402)$ & $0.5541^{* * *}(14.086)$ \\
\hline Observations & 644 & 1064 & 1512 & 1932 & 1288 \\
\hline$R$-squared & 0.2062 & 0.1990 & 0.0923 & 0.2605 & 1.0833 \\
\hline
\end{tabular}

Notes: (1) robust $t$-statistics in parentheses; $(2){ }^{* * *} p<0.01,{ }^{* *} p<0.05$, and ${ }^{*} p<0.1$.

areas. The possible reason for this difference is that, in cities with the high economic development level, the supporting information facilities' hardware and software are already very mature, such as Internet of Things, big data, artificial intelligence, 5G, and other technologies, and the low-carbon economic operation of these cities is in a high position even without SCP, so SCP is just the icing on the cake. For cities with weak economic development, their formalization foundation is weak, but they have the unique advantage of SCP overall planning and promotion. Through the 
systematic layout of cities, they can promote their economic growth, while reducing carbon emissions, thus improving LCE performance. Therefore, the SCP in the central and western regions and noncoastal cities with scarce resources and underdeveloped economy may obtain higher marginal contribution to LCE.

As shown in Table 8, comparing to cities with KEP, non-KEP cities have better positive impacts. While comparing to small- and medium-size cities, SCP has more significant impact on large-scale cities. The possible reason is that cities with KEP have achieved certain results in lowcarbon operation through strict policy control, while SCP may have diminishing marginal effects. However, for those non-KEP cities, the implementation of SCP policy is a new external force, which will stimulate industrial upgrading, structural optimization, and urban innovation in these cities and play an indispensable and significant role in promoting LCE. In addition, the problem of energy efficiency in large cities leads to excessive carbon emissions, which is more prominent. Therefore, the role of SCP in reducing carbon emissions by balancing energy supply and demand may be more significant. Furthermore, the economic agglomeration effect of big cities may make SCP exert better impact.

\section{Conclusions and Policy Implications}

At present, the academic research on smart city mainly focuses on the concept and theory, and there is little research on the influence of SCP on LCE. Existing literature points out that smart cities can optimize the industrial structure, promote urban innovation, and optimize resource allocation which may facilitate the urban LCE. Based on the sample data of 230 cities in China from 2005 to 2018, this paper empirically tests the influence of SCP on LEC by using the DID method and enhances the credibility of the conclusion through the robustness test. And, the research results are as follows: firstly, SCP can significantly improve the LCE performance of cities. Compared with nonpilot cities, SCP pilot cities can increase the LCE performance of cities by about $4.5-5 \%$. Meanwhile, through the analysis of parallel trend hypothesis test and dynamic effect, we can know that, with the deduction of SCP pilot over time, its positive influence on LCE is more and more obvious, and its effect shows a dynamic increasing trend. Secondly, the influence of SCP on LCE is heterogeneous. In China, the LCE of SCP has increased by about $3.4 \%$ in the eastern region, while it has increased by more than $5 \%$ in the central and western regions, which shows that its positive effect is more significant in the central and western regions than in the eastern regions. Similarly, the LCE of noncoastal cities has increased by $4.8 \%$, which is $0.91 \%$ better than that of coastal cities. In addition, the impact on non-KEP cities is more significant than that of KEP cities, and the impact on large cities is more significant than that of small- and medium-sized cities.

Based on the above conclusions, this paper proposes that the construction of smart cities should be based on the characteristics of different regions and explores strategies to promote local LCE performance according to local conditions. Specific recommendations are as follows: based on the advantages of excellent development foundation, environmental protection policy, and good business environment, cities in eastern and coastal areas can integrate with traditional industries and promote the diffusion of the digital low-carbon sharing business model through the digital infrastructure of smart cities in strategic planning, so as to realize the nonlinear feature of increasing marginal effect of smart cities on local LCE and even high-quality economic development. The cities in the central region are adjacent to the eastern region, which has the geographical advantage of further developing LCE. In order to better play the role of SCP, we should actively attract outstanding talents and promote the upgrading and transformation of traditional industries. At the same time, the government should actively learn from the experience of advanced regions, strengthen the shaping of sustainable business environment, and build a knowledge sharing system. Affected by topography and location, the western region is relatively backward in economic development, and the advantages of natural resources have not been brought into full play. Then, driven by the dual policies of SCP and western development, we should actively conceive how to better develop and utilize local new energy sources, such as solar energy and wind energy, and devote ourselves to cultivating characteristic new energy development centers, attracting more social capital and technical resources, and promoting the development of regional LCE.

\section{Conflicts of Interest}

The authors declare that they have no conflicts of interest.

\section{References}

[1] United Nations, World Urbanization on Prospects: The 2018 Revision, United Nations, New York, NY, USA, 2020.

[2] National Bureau of Statistics, China Statistical Yearbook, China Statistics Press, Beijing, China, 2020.

[3] J. Mondschein, A. Clark-Ginsberg, and A. Kuehn, "Smart cities as large technological systems: overcoming organizational challenges in smart cities through collective action," Sustainable Cities and Society, vol. 67, no. 3359, pp. 29-41, 2021.

[4] H. Abusaada and A. Elshater, "Competitiveness, distinctiveness and singularity in urban design: a systematic review and framework for smart cities," Sustainable Cities and Society, vol. 68, no. 2079, pp. 58-62, 2021.

[5] C. F. Calvillo, A. Sánchez-Miralles, J. Villar et al., "Energy management and planning in smart cities," Renewable and Sustainable Energy Reviews, vol. 55, no. 4132, pp. 273-287, 2016.

[6] H. Kim, H. Choi, H. Kang et al., "A systematic review of the smart energy conservation system: from smart homes to sustainable smart cities," Renewable and Sustainable Energy Reviews, vol. 140, no. 774, pp. 2031-2046, 2021.

[7] J. Z. Thellufsen, H. Lund, P. Sorknæs et al., "Smart energy cities in a $100 \%$ renewable energy context," Renewable and Sustainable Energy Reviews, vol. 129, no. 4496, pp. 1124-1136, 2020. 
[8] F. Bifulco, M. Tregua, C. C. Amitrano et al., "ICT and sustainability in smart cities management," Int. J. Public Sect. Manag, vol. 29, no. 147, pp. 132-147, 2016.

[9] R. Cowley and F. Caprotti, "Smart city as anti-planning in the UK," Environment and Planning, vol. 6981, no. 2385, pp. 5890-5907, 2018.

[10] O. B. Nana, "Towards a circular and low-carbon economy: insights from the transitioning to electric vehicles and net zero economy," Journal of Cleaner Production, vol. 256, no. 2803, pp. 3128-3139, 2020.

[11] M. Yu, X. Ding, H. Sun, K. Yu, and D. Zhao, "Role of fuzzy fractional differential equation in the construction of low carbon economy statistical evaluation system," Alexandria Engineering Journal, vol. 59, no. 4, pp. 2765-2775, 2020.

[12] X. Lin, X. Zhu, Y. Han, Z. Geng, and L. Liu, "Economy and carbon dioxide emissions effects of energy structures in the world: evidence based on SBM-DEA model," The Science of the Total Environment, vol. 729, no. 43, Article ID 138947, 2020.

[13] M. Mohsin, A. K. Rasheed, H. Sun et al., "Developing low carbon economies: an aggregated composite index based on carbon emissions," Sustainable Energy Technologies and Assessments, vol. 35, no. 604, pp. 365-374, 2019.

[14] M. Mohsin, F. Taghizadeh-Hesary, N. Panthamit et al., "Developing Low Carbon Finance Index: Evidence from Developed and Developing Economies," Finance Research Letters, 2020.

[15] M. R. Hasan, T. C. Roy, Y. Daryanto, and H.-M. Wee, "Optimizing inventory level and technology investment under a carbon tax, cap-and-trade and strict carbon limit regulations," Sustainable Production and Consumption, vol. 25, no. 118, pp. 604-621, 2021.

[16] J. Yin, M. Zheng, and J. Chen, "The effects of environmental regulation and technical progress on $\mathrm{CO} 2$ Kuznets curve: an evidence from China," Energy Policy, vol. 77, pp. 97-108, 2015.

[17] M. Song, S. Wang, and J. Sun, "Environmental regulations, staff quality, green technology, R\&D efficiency, and profit in manufacturing," Technological Forecasting and Social Change, vol. 133, pp. 1-14, 2018.

[18] W. Li, W. Sun, G. Li, P. Cui, W. Wu, and B. Jin, "Temporal and spatial heterogeneity of carbon intensity in China's construction industry," Resources, Conservation and Recycling, vol. 126, pp. 162-173, 2017.

[19] M. M. Rahman and M. A. Kashem, "Carbon emissions, energy consumption and industrial growth in Bangladesh: empirical evidence from ARDL cointegration and Granger causality analysis," Energy Policy, vol. 110, pp. 600-608, 2017.

[20] E. Abokyi, P. Appiah-Konadu, F. Abokyi, and E. F. OtengAbayie, "Industrial growth and emissions of $\mathrm{CO} 2$ in Ghana: the role of financial development and fossil fuel consumption," Energy Reports, vol. 5, pp. 1339-1353, 2019.

[21] F. Zhang, X. Deng, F. Phillips et al., "Impacts of industrial structure and technical progress on carbon emission intensity: evidence from 281 cities in China," Technol Forecast Soc, vol. 154, pp. 435-447, 2020.

[22] F. Abbasi and K. Riaz, "CO2 emissions and financial development in an emerging economy: an augmented VAR approach," Energy Policy, vol. 90, pp. 102-114, 2016.

[23] S. Nasreen, S. Anwar, I. Ozturk et al., "Financial stability, energy consumption and environmental quality: evidence from south Asian economies," Renewable and Sustainable Energy Reviews, vol. 67, pp. 1105-1122, 2017.

[24] M. Shahbaz, M. A. Nasir, and D. Roubaud, "Environmental degradation in France: the effects of FDI, financial development, and energy innovations," Energy Economics, vol. 74, pp. 843-857, 2018.

[25] K. K. Gokmenoglu and M. Sadeghieh, "Financial development, CO2 emissions, fossil fuel consumption and economic growth: the case of Turkey," Strategic Planning for Energy and the Environment, vol. 38, no. 4, pp. 7-28, 2019.

[26] A. Shi, "The impact of population pressure on global carbon dioxide emissions, 1975-1996: evidence from pooled crosscountry data," Ecol",Econ, vol. 44, no. 31, pp. 29-42, 2003.

[27] T. Menz and H. Welsch, "Population aging and carbon emissions in OECD countries: accounting for life-cycle and cohort effects," Energy Economics, vol. 34, no. 3, pp. 842-849, 2012.

[28] C. Zhang and Z. Tan, "The relationships between population factors and China's carbon emissions: does population aging matter?" Renewable and Sustainable Energy Reviews, vol. 65, pp. 1018-1025, 2016.

[29] M. Khanna and W. R. Q. Anton, "Corporate environmental management: regulatory and market-based incentives," Land Economics, vol. 78, no. 4, pp. 539-558, 2002.

[30] T. Huo, X. Li, W. Cai et al., "Exploring the impact of urbanization on urban building carbon emissions in China: evidence from a provincial panel data model," Sustainable Cities and Society, vol. 56, pp. 437-449, 2012.

[31] L. Zhang, R. Long, W. Li et al., "Potential for reducing carbon emissions from urban traffic based on the carbon emission satisfaction: case study in Shanghai," Journal of Transport Geography, vol. 85, pp. 145-159, 2020.

[32] X. Liu, Y. Wang, Q. Song et al., "Sources of carbon emissions in the process of urbanization," China Population", Resources and Environment, vol. 25, no. 1, pp. 61-66, 2015.

[33] X. L. Zhao and Y. Zhao, "Environmental regulation policy and the behavior of enterprisesd the evidence from high energy consuming enterprises," Science Research Management, vol. 10, pp. 130-138, 2015.

[34] R. L. Glicksman and D. Earnhart, "Effectiveness of government interventions at inducing better environmental performance: does effectiveness depend on facility or fifirm feature," Boston College Environmental Affairs Law Review, vol. 35, no. 1, pp. 1-33, 2008.

[35] T. Yao, Z. Huang, and W. Zhao, "Are smart cities more ecologically efficient? Evidence from China," Sustainable Cities and Society, vol. 60, pp. 1-9, 2020.

[36] M. Babar and A. S. Khattak, "Energy aware smart city management system using data analytics and Internet of Things," Sustainable Energy Technologies and Assessments, vol. 44, no. 100992, pp. 2213-1388, 2021.

[37] H. Luo, H. Cai, H. Yu, Y. Sun, Z. Bi, and L. Jiang, “A shortterm energy prediction system based on edge computing for smart city," Future Generation Computer Systems, vol. 101, pp. 444-457, 2019.

[38] A. Ahl, M. Yarime, K. Tanaka, and D. Sagawa, "Review of blockchain-based distributed energy: implications for institutional development," Renewable and Sustainable Energy Reviews, vol. 107, pp. 200-211, 2019.

[39] M. Mihaylov, S. Jurado, N. Avellana et al., "Virtual currency for trading of renewable energy in smart grids," in Proceedings of the International Conference on the European Energy Market, EEM, pp. 1-6, Krakow, Poland, May 2014.

[40] J. J. Sikorski, J. Haughton, M. Kraft et al., "Blockchain technology in the chemical industry: machine-to-machine electricity market," Applied Energy, vol. 195, pp. 234-246, 2017. 
[41] M. Angelidou, "The role of smart city characteristics in the plans of fififteen cities," Journal of Urban Technology, vol. 24, no. 4, pp. 2-28, 2017.

[42] A. Caragliu and C. F. Del Bo, "The economics of smart city policies," Scienze Regionali, vol. 17, no. 1, pp. 81-104, 2018.

[43] A. Caragliu and C. F. Del Bo, "Smart innovative cities: the impact of smart city policies on urban innovation," Technological Forecasting and Social Change, vol. 39, pp. 445-458, 2018.

[44] S. Zygiaris, "Smart city reference model: assisting planners to conceptualize the building of smart city innovation ecosystems," Journal of the Knowledge Economy, vol. 4, no. 2, pp. 217-231, 2013.

[45] A. Caragliu and C. F. Del Bo, "Smart innovative cities: the impact of smart city policies on urban innovation," Technological Forecasting and Social Change, vol. 40, no. 162, pp. 517-529, 2018.

[46] I. Capdevila and M. I. Zarlenga, "Smart city or smart citizens? The Barcelona case," Journal of Strategy and Management, vol. 8, no. 3, pp. 266-282, 2015.

[47] S. Kraus, C. Richter, S. Papagiannidis, and S. Durst, "Innovating and exploiting entrepreneurial opportunities in smart cities: evidence from Germany," Creativity and Innovation Management, vol. 24, no. 4, pp. 601-616, 2015.

[48] J. R. Gil-Garcia, J. Zhang, and G. Puron-Cid, "Conceptualizing smartness in government: an integrative and multidimensional view," Government Information Quarterly, vol. 33, no. 3, pp. 524-534, 2016.

[49] T. Wang, Y. Liang, W. Jia, M. Arif, A. Liu, and M. Xie, "Coupling resource management based on fog computing in smart city systems," Journal of Network and Computer Applications, vol. 135, pp. 11-19, 2019.

[50] Y. T. Yu and N. Zhang, "Does smart city policy improve energy effiffifficiency? Evidence from a quasi-natural experiment in China," Journal of Cleaner Production, vol. 316, no. 4, pp. 257-270, 2019.

[51] A. H. Sodhro, "Towards an optimal resource management for IoT based Green and sustainable smart cities," Journal of Cleaner Production, vol. 118, no. 4620, pp. 341-359, 2019.

[52] Li Jing, "Resource optimization scheduling and allocation for hierarchical distributed cloud service system in smart city," Future Generation Computer Systems, vol. 107, pp. 247-256, 2020.

[53] R. Kunst, L. Avila, E. Pignaton, S. Bampi, and J. Rochol, "Improving network resources allocation in smart cities video surveillance," Computer Networks, vol. 134, no. 7, pp. 228-244, 2018.

[54] C. Zhou and Y. Tan, "The impact of a carbon trading pilot policy on theLow-carbon economic transformation in China-an empirical analysis based on a DID model," Soft Science, vol. 10, pp. 36-42, 2018.

[55] Z. Zhou and J. Hu, "Evaluation of low carbon economy development efficiency based on a super-SBM model," Resources Science, vol. 35, no. 12, pp. 2457-2466, 2013.

[56] H. Fukuyama and W. L. Weber, "A directional slacks-based measure of technical inefficiency," Socio-Economic Planning Sciences, vol. 43, no. 4, pp. 274-287, 2009.

[57] M. Song, X. Zhao, and Y. Shang, "The impact of low-carbon city construction on ecological efficiency: empirical evidence from quasi-natural experiments," Resources, Conservation, and Recycling, vol. 157, no. 104, pp. 77-89, 2020.

[58] L. Xia, S. Dai, and Y. Li, "Research on the mechanism of smart city policy promoting urban technological innovation-based on the dual perspective of evolution characteristics and transmission effect," Research and Development Management, vol. 32, no. 4, pp. 12-24, 2020.

[59] X. Cai, Y. Lu, M. Wu, and L. Yu, "Does environmental regulation drive away inbound foreign direct investment? evidence from a quasi-natural experiment in China," Journal of Development Economics, vol. 123, pp. 73-85, 2016.

[60] Q. Liu and L. D. Qiu, "Intermediate input imports and innovations: evidence from Chinese firms' patent filings," Journal of International Economics, vol. 103, no. 186, pp. 166-183, 2016. 